
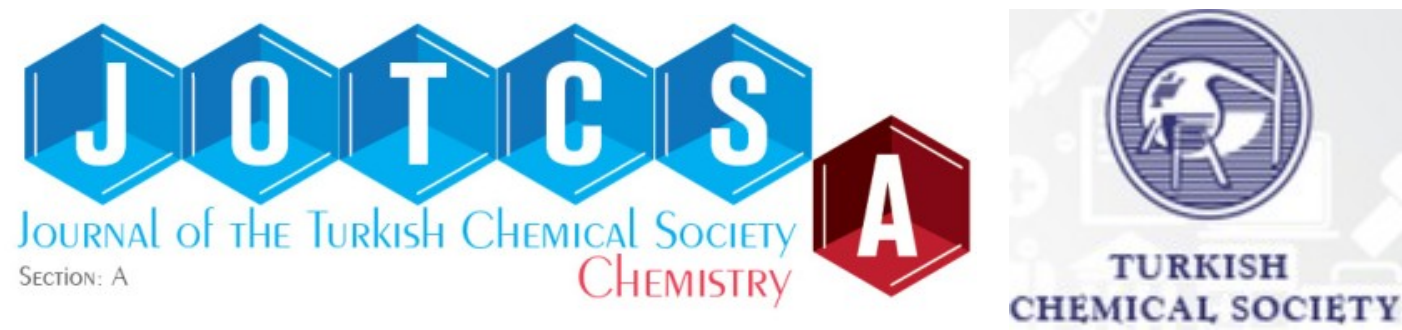

\title{
Drug Discovery and Treatment of an Emerging Pandemic Infection Covid-19
}

\author{
Mishra Arunesh K. ${ }^{1}$ iD $\triangle$, Pratibha ${ }^{1}$ iD $\triangle$, and Das Ratnesh ${ }^{1 *}$ iD $\triangle$ \\ ${ }^{1}$ Department of Chemistry, Dr. Harisingh Gour Central University, Sagar- 470003 (M.P.), INDIA \\ IGNTU, Amarkantak, M.P., INDIA
}

\begin{abstract}
In the last decades, two serious coronaviruses have appeared in humans and animals, SARS$\mathrm{CoV}$ (severe acute respiratory syndrome) and MERS-CoV (middle east respiratory syndrome) are also contagious viruses that causes ARDS stands for acute respiratory distress syndrome. SARS-CoV in 2003 and MERS-CoV in 2012 are characterized as a high mortality rate. This novel human respiratory coronaviruses, also known as SARS n-CoV or SARS-CoV-2, are needed to rapidly provide therapeutic options to reduce and prevent the spread of this outbreak. For such infections, there are currently no scientifically approved precautions or anti - viral products authorized.; therefore, effective remedial and preventive strategies have to be developed that can be easily applied to this newly emerging epidemic. In addition to all these, some therapeutic options are also being evaluated that are used for Covid-19, which includes inhibitory virus molecules or molecules that target specific replication and transcription enzymes. Since the drugs remdesivir, lopinavir-ritonavir, favipiravir, camostat mesylate, chloroquine, and hydroxychloroquine were originate closely stand high successful in controlling infection, Covid-19 looks promising. The research on Covid-19, discuss the efficacy of the several drug and vaccines against Covid-19 and previous outbreaks of SARS and MERS, and provide recommendations for new modes of treatment, assessment, and clinical research on such terrible epidemic. This paper will summarize and discuss the main biological characteristics of SARS-CoV-2 and the current scenario of emerging Covid-19 infections, as well as explain the current therapeutic medications treating Covid-19, based on the clinical trial data.
\end{abstract}

Keywords: 2019-new coronavirus, epidemic, vaccines \& antiviral drugs, acute respiratory distress syndrome (ARDS), remdesivir, chloroquine.

Submitted: March 27, 2021. Accepted: June 13, 2021.

Cite this: Mishra AK, Pratibha, Das R. Drug Discovery and Treatment of an Emerging Pandemic Infection Covid-19. JOTCSA. 2021;8(3):715-22.

DOI: https://doi.org/10.18596/jotcsa.897044.

*Corresponding author. E-mail: ratneshdas1@gmail.com.

\section{INTRODUCTION}

The World Health Organization (WHO) expressed concern after taking cognizance of this after coming to light on several fast-spreading viral pneumonia cases due to unknown reasons in the Hubei province of Wuhan city of China on December 31, 2019. Later, on January 7, 2020, it was self-confirmed by China's scientific research institutes that the real reason behind viral pneumonia serious acute respiratory symptoms would be a new form of coronavirus. SARS-CoV-2 is a virus that causes SARS (1). After which, by the international committee on taxonomy of viruses on February 11, 2020, the novel coronavirus was named SARS-CoV-2 is a coronavirus that causes extreme acute respiratory syndrome (2). The WHO then dubbed the SARS-CoV-2-caused disorder Coronavirus 2019 (Covid-19) (3). Severe acute respiratory syndrome coronavirus 2 (SARS-CoV-2) viruses are single-stranded RNA viruses with $\sim 30,000$ nucleotides and a group of highly diverse, non-fragmented positive-sense, that In animal species, it causes infectious, enteric, hepatic, and 
neural ailments, including human belong to the order Nidovirales, family Coronaviridae, genus Betacoronavirus, and the species belong to the severe acute respiratory syndrome-related coronavirus (SARS-CoV) (4-8).

In the late 1960s, Tyrrell, one of the virologists with his colleagues, was investigating the effects of the virus on humans. While observed within an electron microscope, infectious bronchitis virus, mouse hepatitis virus, and swine's transmissible gastroenteritis virus were all shown to still be morphologically similar (9). This new virus group was called coronavirus due to a corona-like surface and was future authoritatively recognized as the virus's novel gene (10). As research on the pathogenetics and epidemiology of humanoid coronaviruses progressed, the character of animal coronaviruses was increasing quickly. In which it was observed that coronaviruses cause disorder trendy many animal classes, plus rats, chickens, dogs, cats, mice, and pig are all examples of animals. The research involved in animal studies focuses only on respiratory disorders. The key research included gastrointestinal, hepatitis, and encephalitis in mice; the pathogenesis of these disorder conditions remained diverse also multipart, suggesting that the gene as an entire could cause an extensive range of diseases (11). Much has been known about the epidemiology of human respiratory coronaviruses using serological techniques. According to recent studies, respiratory coronavirus infections are more common in temperate climates in wintertime and spring than in the summer and decrease (12). In 2002-2003, SARS, a severe acute respiratory syndrome known as coronavirus, emerged from southerly China, spreading worldwide as an epidemic (13).

Many species, including cats, cows, bats, horses, and humans, are susceptible to coronavirus pathogens. There are currently seven forms of coronaviruses identified, four of which (229E, NL63, OC43, and KHU1) cause slight to modest breathing contaminations similar to the general cold, which do not have many side effects and these actions are fatal. One and two types, the SARS-CoV and the MERS-CoV, can origin severe breathing infections that are more fatal, causing humans and animals vulnerable to severe illnesses. Whereas the seventh type recently discovered in China is the novel coronavirus or Covid-19 that occurs in humans, Covid-19 is primarily respiratory or gastrointestinal tap affects humans through infection whose symptoms are that they can be up spironia as more severe lower respiratory infections from the common cold (14). Many diseases in humans are spread by coronaviruses, most of which are associated with mild clinical symptoms, including SARS-CoV, a novel betacavavavirus that originates from Guangdong, southern China is spread all over the world (15).

\section{Severe acute respiratory syndrome coronavirus 2 (SARS-CoV-2)}

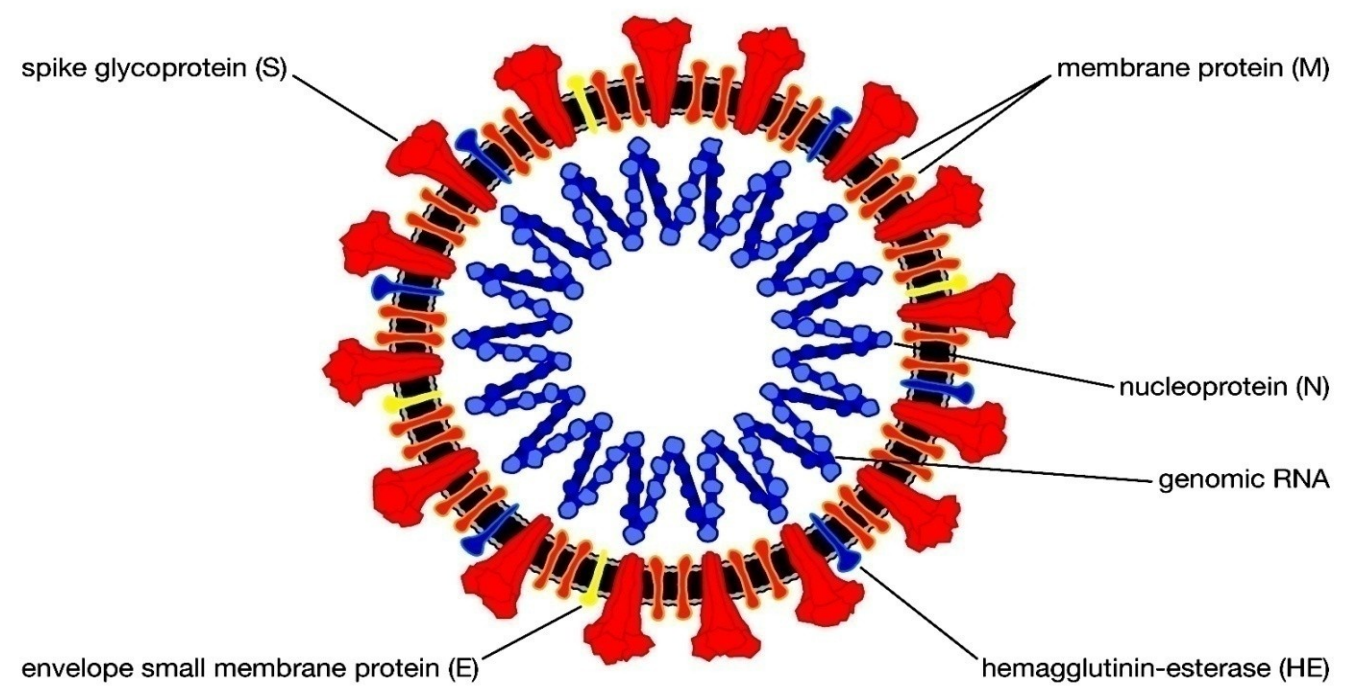

Figure 1. Cartoon illustration of the severe acute respiratory syndrome SARS CoV-2 structure.

The nucleic acid of the SARS CoV-2 virus is around $30 \mathrm{~kb}$ long, polyadenylated in a positive manner and single-stranded. RNA is the major identified viral RNA code meant for a large poly-protein
(Figure 1). The mutation is a natural phenomenon of nature in which climate change also plays an important role. Furthermore, if two viruses infect the same cell simultaneously, coronavirus (SARS- 
CoV-2) is capable of genetic recombination. The cytoplasm of infected cells is where all coronaviruses originate, from the endoplasmic reticulum to the cytoplasmic vesicles. Within that time period, the vesicles are then extruded or expelled from of the cell, as well as the cell is killed (16). Viruses include structural S-spike proteins (external spikey glycoproteins), N-nucleocapsid proteins (which are found within the phospholipid bilayer), and non-structural proteins are all encoded by separate genetic loci on the virus's RNA. The nucleocapsid, which is made up of genomic RNA and nucleocapsid proteins, is at the heart of the virion (17).

\section{Pandemic Outbreak in Current Scenario}

At present, the cases of coronavirus in the whole world have reached over 9,060,870, indicating that North America, India, Brazil, Turkey, and Russia are the main pillars of Covid-19, Europe (France, Britain, Italy, Germany, Spain, etc.) the major in the Americas. The United States and East Asia
China are mainly vulnerable to the coronavirus, which has resulted in a huge quantity of expiries and growing rates. The speedy growth of the worldwide coronavirus is also happening in the countries of the Indian subcontinent, which is a large population center; the WHO has also continuously issued guidelines for health care and control strategies to countries like India, thorough exchange of research, technology and public health information for active illness regulator and protective administration must be Radan. The best way to avoid disease transmission is to use the most widely adopted practice, social distinction, and work from a home model, which includes limitations on foreign and local visits, as well as complete lockdown over a broad geographic region. These countries' revealed activities include sanitation adaptation through technology, mass diagnosis and quarantine, and complete lockdown. It is critical to comprehend and implement their preventive public health model as a strategy.

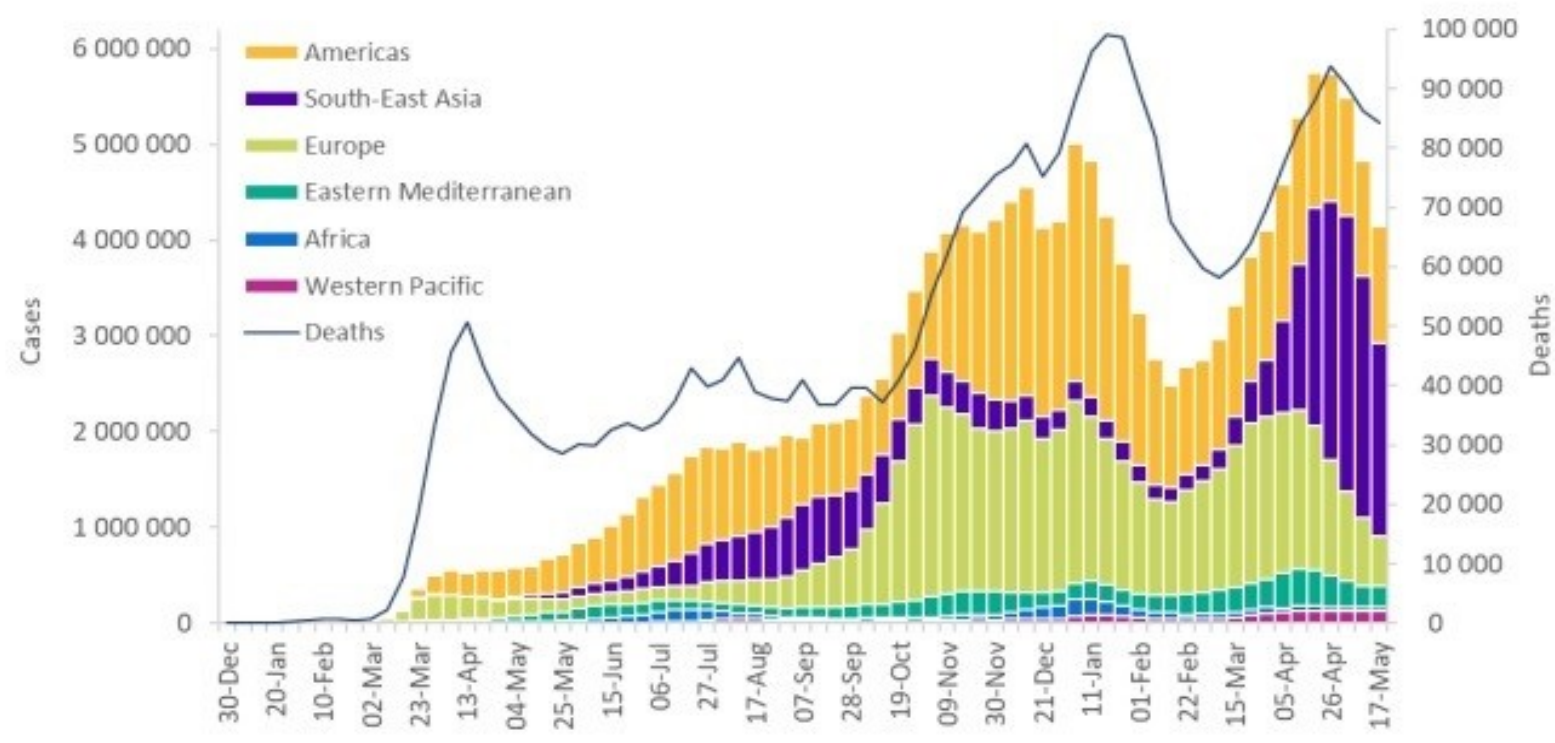

Figure 2: Covid-19 cases reported weekly by WHO Region, and global deaths, as of 23 May 2021**

From December 31, 2019, to May 22, 2021, conferring to the WHO, there are $162,773,940$ cases of Covid-19 universal (giving to the case definitions and trial strategies applied in the affected countries), and 3,375,573 worldwide deaths occurred as of May 22, 2020, supreme figures of cases have remained testified in USA $(32,605,236)$, India $(24,965,463)$, Brazil $(15,856,534)$, France $(5,783,787)$, Turkey $(5,117,374)$, Russia $(4,949,573)$, United Kingdom $(4,450,781)$, Italy $(4,159,122)$, Germany $(3,598,846) \quad$ Spain $(3,598,452)$, Argentina
$(3,514,683)$, Colombia $(3,103,333)$, Poland $(2,855,190)$ and Iran $(2,751,166)$. The global epidemic caused by covid-19 has caused the highest number of deaths $(605,805)$ in the United States so far and India's death toll $(274,390)$. The deaths reported by other countries like Brazil $(434,715)$, France $(106,859)$ Turkey $(44,760)$, Russia $(116,211)$, United Kingdom $(127,679)$, Italy $(124,126)$, Germany $(86,160)$ Spain $(79,281)$, Argentina $(70,253)$, Colombia $(80,780)$, Poland $(71,675)$ and Iran $(76,936)$. 


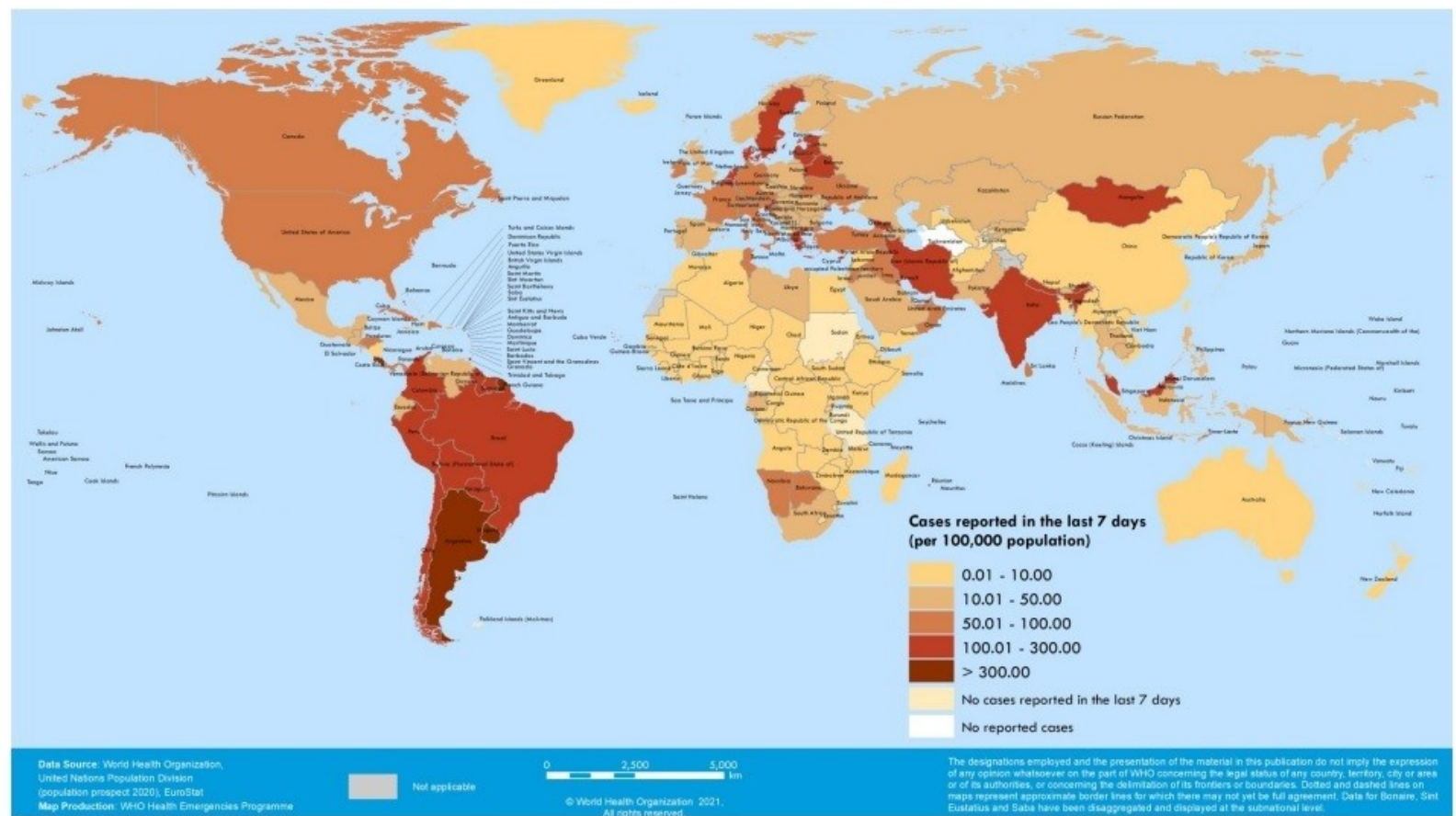

Figure 3: Covid-19 cases per 100,000 population reported by countries, territories, and areas, 17 May 23 May $2021^{* *}$

Antiviral Drugs with Therapeutic Potential Against the SARS-CoV-2

In direction of avoid the rapid growing of Covid-19, intensive monitoring of disease warrants and rapid dissemination of isolation protocols is vital. It is well known that no drug or vaccine has been developed yet. That is why the aim of current treatment strategies is only symptomatic care and oxygen therapy. However, prophylactic vaccination is crucial for the early prevention of an epidemic or pandemic related to Covid-19. Here is no finding of drug for the handling of Covid-19 contamination or prophylactic drugs. The patient's condition and the habit of handwashing, face covers, and other hygiene steps are all essential in treating respiratory aerosol/droplet infections caused by patients. Covid-19 will reduce the risk of transmission and be helpful in patient care due to this. Diagnostic testing of the effectiveness of the new antiviral drug Remedisvir. The first use of this drug has been used on various animals in diseases related to the Ebola virus, SARS, and MERS virus (18). Scientists around the world are increasingly trying to find vaccines and drugs to treat infections transmitted by Covid-19. More than 30 agents, including Due to this type of research, natural products from Western medicine and conventional Chinese medicines have been identified as having emphatic effectiveness against Covid-19. Any of these compounds have been tested in clinical trials and have shown promise in combating Covid-19 (19). For Covid-19 treatment, the National Health Commission of the People's Republic of China recommends IFN- and lopinavir/ritonavir. This recommendation is focused on past studies have shown that this drugs lower death rates in patients undergoing SARS. In the most recent version of the Guidelines, antivirals such as interferon (IFN-), lopinavir/ritonavir, chloroquine phosphate, ribavirin, and arbidol are recommended for the prevention, diagnosis, and treatment of novel coronaviruses (20). 


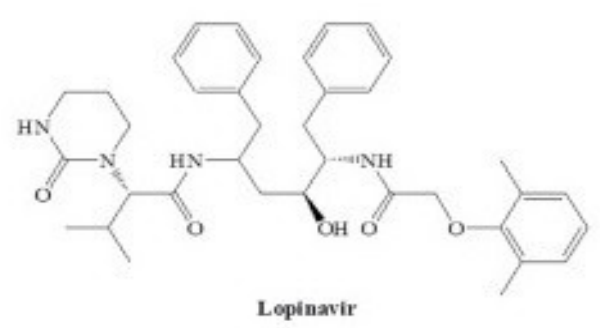

Lopinavir

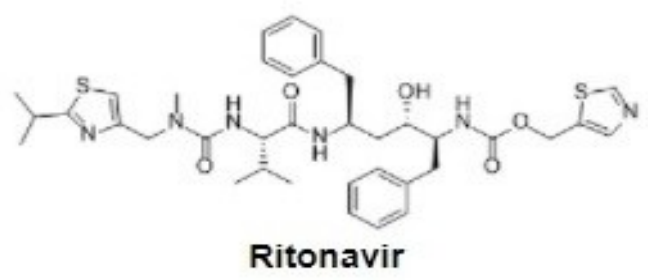

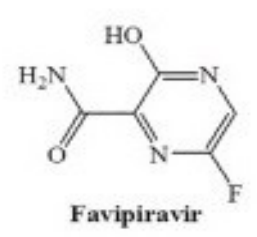

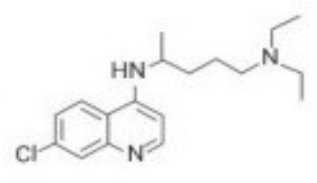

chloroquine
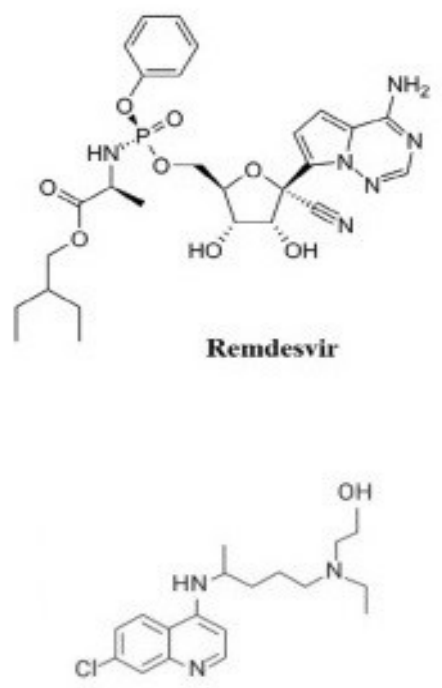

Hydroxychloroquine

Figure 4: Chemical structural formula of some therapeutic agents (drugs) against SARS CoV-2.

Previous research has shown that the RNA polymerase is responsible for virus-related duplication in host cells and that the remediesavir drug acts as an inhibitor, preventing infection from being transmitted and in rhesus macaques as a pre-proliferation prophylaxis as a prevention, rehabilitation therapy, and it reduced disorder, virus replication, and lung injury. Several countries around the world, including the United States, are increasingly using hydroxychloroquine drugs for patients with uncontrolled Covid-19 infection, which showed strong in-vitro movement in contradiction of SARS-COV-2 preclinical proliferation (21). Recent research has found that the IFN- compound, a wide-ranging antiviral agent widely cast-off to take care of hepatitis, weakens the life cycle and reduces the effects of infection by disrupting SARS-CoV reproduction in vitro and decreases the effects of infection (22). Chu et al. discovered that ribavirin has a wide-ranging of antiviral effects then that lopinavir/ritonavir has SARS-CoV motion in vitro against SARS CoV-2 in medical studies (23). Chloroquine is an antimalarial medicine that stayed discovered to have wide-ranging antiviral effects in 2006 (24). Arbidol, an antiviral drug used to treat the influenza virus, was found to effectively prevent SARS-CoV-2 contamination in vitro at concentrations of 10 to $30 \mu \mathrm{M}$ in one sample (25). China approved Favipiravir, an anti-influenza medication, to treat novel influenza on February 15,2020 . This drug is currently being tested for Covid-19 therapy. Favipiravir is a new type of RNA-dependent RNA polymerase (RDRP) inhibitor with anti-influenza virus properties and the ability to stop the reproduction of flavi-, alpha-, phyllo-, market-region, noro- and other RNA viruses (26). Patients with extreme Covid-19 pneumonia with hyper inflammatory syndrome and acute respiratory failure reacted to tocilizumab effectively and consistently, with substantial thereupetic changes, according to a recent prospective study in a single centre with 100 patients from Italy (27). Dexamethasone was found to reduce 28 -day mortality in patients hospitalised with Covid-19 who were getting either intrusive respiratory support or oxygen alone at the time of trial, but not in those who were not getting mechanical ventilation (28). Caly et al., reported that Ivermectin, an FDA-approved antiparasitic drug that has previously demonstrated to have broad-spectrum anti-viral activity in vitro, is an inhibitor of the SARS-CoV-2 virus (29).

\section{Vaccines Against SARS CoV-2}

Policy makers from various countries have traditionally demanded a growing number of clinical trials with a majority of patients and a high number of resources for human vaccine production. These safeguards conclude that the best vaccine product is secure and appropriate for various demographic groups prior to commercialization. Unlike SARS and MERS, which appeared to reconcile spontaneously after territorial pandemics, the global scale of the Covid19 outbreaks has rendered vaccine production a top priority. This pressing need has prompted a variety of approaches to vaccine production. Regulatory bodies from around the world have demanded that the number of clinical trials on corona virus-infected people be increased, as well as the testing of different vaccines. Before being 
approved for commercial use, these studies ensure that the final vaccine product is safe and effective for different population subgroups (30). The WHO has also used this dataset to better understand global vaccination access discrepancies, utilising this evidence to support recommendations for increased financial support for COVAX, a WHObacked worldwide project aiming at ensuring equitable access to Covid-19 vaccinations (31).

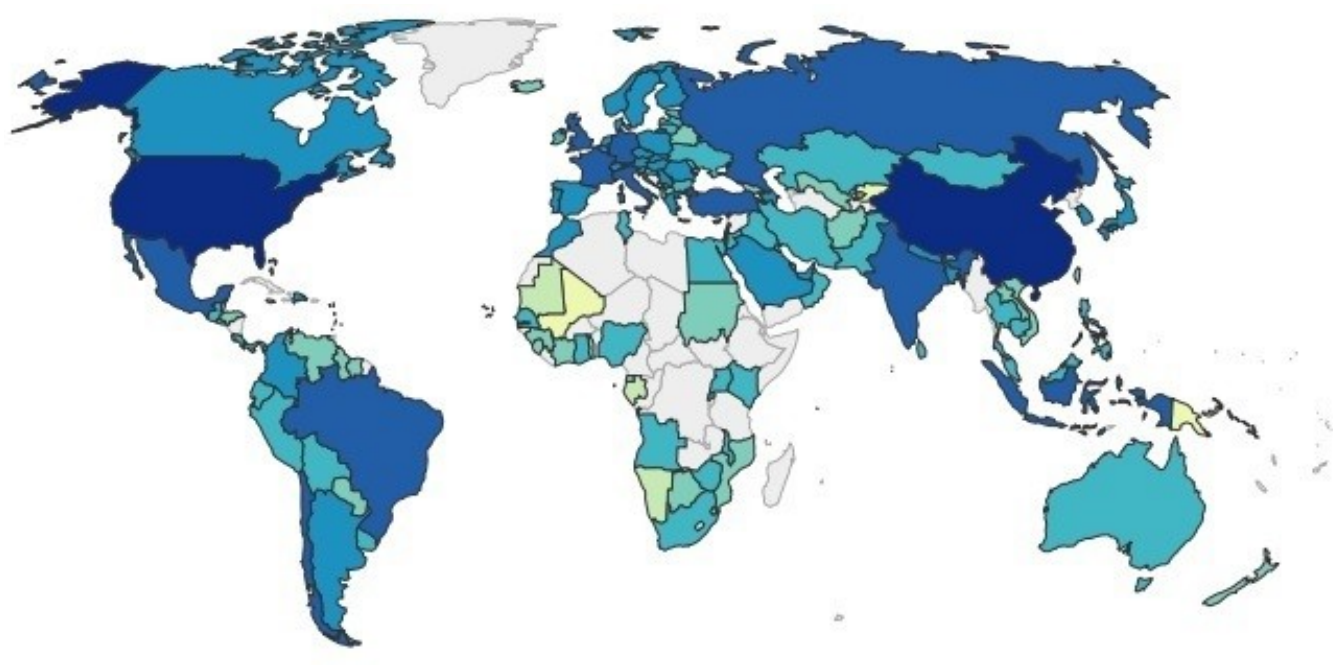

No data 100 1,000 10,000

Figure 5: Cumulative number of Covid-19 doses administered by country. Total number of Covid-19 vaccine doses administered as of 7 April 2021 (Ref. 29).

More than 100 vaccines against SARS-CoV-2 are being developed, according to WHO reports. Vaccination can help contain SARS-COV-2 epidemics by preventing infection or lowering the severity of sickness, virus shedding, and spread. SARS-COV-2 vaccines have been developed using DNA and RNA-based vaccines, subunit (recombinant protein) vaccines, viral vector vaccines, live-attenuated virus vaccines, recombinant protein vaccines and inactivated virus vaccines (32).

\section{CONCLUSION}

Covid-19, an infection that has become a global epidemic and is spreading at a very alarming rate worldwide. Side effects of Covid-19 can be predicted to cause more infection than SARS or MERS and also lead to faster deaths. Assuming WHO, it can be said that SARS-CoV-2 is more infectious than SARS or MERS. As the Covid-19 outbreak banquets crosswise the biosphere, scientists are scrambling to find medications that may be successful in fighting the virus. There are currently no antivirals that have been shown to be effective against Covid-19. Covid-19 is being treated with medicines that have previously been used to treat other diseases. Efforts are also being made to create medical tests to determine the effectiveness of the medications. However, given the current severe global epidemic situation and the urgent need for medical treatment, further studies should be undertaken as soon as possible to identify a new vaccine or treatment and to effectively manage this health crisis. Covid-19 is a virus that can be spread from person to person. Covid-19 can be effectively minimized by interventions such as comprehensive contact tracing followed by quarantine and isolation, by the influence of travel bans, wearing covers, wash hands, and sanitizing outsides.

\section{REFERENCES}

1. Wang $M$, Zhou M, Ji G, Ye L, Cheng $Y$, Feng $Z$, et al. Mask crisis during the Covid-19 outbreak. European Review for Medical and Pharmacological Sciences. 2020;3397-9. URL: https://www.europeanreview.org/wp/wp-content/u ploads/3397-3399.pdf.

2. International Committee on Taxonomy of Viruses. The ICTV Report on Virus Classification and Taxon Nomenclature. June 14, 2021 (https://talk.ictvonline.org/ictv-reports/)

3. Ghebreyesus TA, Swaminathan S. Scientists are sprinting to outpace the novel coronavirus. The Lancet. 2020 Mar;395(10226):762-4. DOI: https://doi.org/10.1016/S0140-6736(20)30420-7.

4. Huang C, Wang Y, Li X, Ren L, Zhao J, Hu Y, et 
al. Clinical features of patients infected with 2019 novel coronavirus in Wuhan, China. The Lancet. 2020 Feb;395(10223):497-506. DOI: https://doi.org/10.1016/S0140-6736(20)30183-5.

5. Rota PA. Characterization of a Novel Coronavirus Associated with Severe Acute Respiratory Syndrome. Science. 2003 May 30;300(5624):1394-9. DOI: https://doi.org/10.1126/science.1085952.

6. Woo PCY, Lau SKP, Huang $Y$, Yuen $\mathrm{K}-\mathrm{Y}$. Coronavirus Diversity, Phylogeny and Interspecies Jumping. Exp Biol Med (Maywood). 2009 Oct;234(10):1117-27.

DOI:

https://doi.org/10.3181/0903-MR-94.

7. Chan JFW, Li KSM, To KKW, Cheng VCC, Chen $\mathrm{H}$, Yuen $\mathrm{K}-\mathrm{Y}$. Is the discovery of the novel human betacoronavirus 2c EMC/2012 (HCoV-EMC) the beginning of another SARS-like pandemic? Journal of Infection. 2012 Dec;65(6):477-89. DOI: https://doi.org/10.1016/j.jinf.2012.10.002.

8. Chan JF-W, Lau SK-P, Woo PC-Y. The emerging novel Middle East respiratory syndrome coronavirus: The "knowns" and "unknowns." Journal of the Formosan Medical Association. 2013 Jul;112(7):372-81.

https://doi.org/10.1016/j.jfma.2013.05.010.

9. McIntosh K, Becker WB, Chanock RM. Growth in suckling-mouse brain of "IBV-like" viruses from patients with upper respiratory tract disease. Proceedings of the National Academy of Sciences. 1967 Dec 1;58(6):2268-73. DOI: https://doi.org/10.1073/pnas.58.6.2268.

10. Pal M, Berhanu G, Desalegn C, Kandi V. Severe Acute Respiratory Syndrome Coronavirus-2 (SARSCoV-2): An Update. Cureus [Internet]. 2020 Mar 26 [cited 2021 Jun 14]; URL: https://www.cureus.com/articles/29589-severeacute-respiratory-syndrome-coronavirus-2-sarscov-2-an-update

11. Haring J, Perlman S. Mouse hepatitis virus. Current Opinion in Microbiology. 2001 Aug $1 ; 4(4): 462-6$.

DOI: https://doi.org/10.1016/S1369-5274(00)00236-8.

12. Mcintosh K, Kapikian AZ, Turner HC, Hartley JW, Parrott RH, Chanock RM. Seroepidemiologic Studies of Coronavirus Infection in Adults and Children1. American Journal of Epidemiology. 1970 Jun;91(6):585-92. DOI: https://doi.org/10.1093/oxfordjournals.aje.a12117 1.

13. Peiris J, Lai S, Poon L, Guan Y, Yam L, Lim W, et al. Coronavirus as a possible cause of severe acute respiratory syndrome. The Lancet. 2003 Apr;361(9366):1319-25.

DOI:

https://doi.org/10.1016/S0140-6736(03)13077-2.

14. Zhu N, Zhang D, Wang W, Li X, Yang B, Song J, et al. A Novel Coronavirus from Patients with Pneumonia in China, 2019. N Engl J Med. 2020 Feb $20 ; 382(8): 727-33$.

DOI:

https://doi.org/10.1056/NEJMoa2001017.

15. Peiris JSM, Guan Y, Yuen KY. Severe acute respiratory syndrome. Nat Med. 2004 Dec; 10(S12): S88-97.

https://doi.org/10.1038/nm1143.

16. Holmes KV. SARS coronavirus: a new challenge for prevention and therapy. J Clin Invest. 2003 Jun 1;111(11):1605-9. DOI: https://doi.org/10.1172/JCI18819.

17. Fehr AR, Perlman S. Coronaviruses: An Overview of Their Replication and Pathogenesis. In: Maier $\mathrm{HJ}$, Bickerton $\mathrm{E}$, Britton $\mathrm{P}$, editors. Coronaviruses [Internet]. New York, NY: Springer New York; 2015 [cited 2021 Jun 14]. p. 1-23. (Methods in Molecular Biology; vol. 1282). URL: http://link.springer.com/10.1007/978-1-49392438-7 1.

18. de Wit E, Feldmann F, Cronin J, Jordan R, Okumura A, Thomas $T$, et al. Prophylactic and therapeutic remdesivir (GS-5734) treatment in the rhesus macaque model of MERS-CoV infection. Proc Natl Acad Sci USA. 2020 Mar 24;117(12):6771-6. DOI: https://doi.org/10.1073/pnas.1922083117.

19. Qiu T, Liang S, Dabbous M, Wang Y, Han R, Toumi $M$. Chinese guidelines related to novel coronavirus pneumonia. Journal of Market Access \& Health Policy. 2020 Jan 1;8(1):1818446. DOI: https://doi.org/10.1080/20016689.2020.1818446.

20. Ko W-C, Rolain J-M, Lee N-Y, Chen P-L, Huang $\mathrm{C}-\mathrm{T}$, Lee P-I, et al. Arguments in favour of remdesivir for treating SARS-CoV-2 infections. International Journal of Antimicrobial Agents. 2020 Apr;55(4):105933.

DOI: https://doi.org/10.1016/j.ijantimicag.2020.105933

21. Gautret $P$, Lagier J-C, Parola P, Hoang VT, Meddeb L, Mailhe M, et al. Hydroxychloroquine and azithromycin as a treatment of Covid-19: results of an open-label non-randomized clinical trial. International Journal of Antimicrobial Agents. 2020 Jul;56(1):105949.

DOI: https://doi.org/10.1016/j.ijantimicag.2020.105949

22. Stockman LJ, Bellamy R, Garner P. SARS: 
Systematic Review of Treatment Effects. Low D, editor. PLoS Med. 2006 Sep 12;3(9):e343. DOI: https://doi.org/10.1371/journal.pmed.0030343.

23. Chu CM. Role of lopinavir/ritonavir in the treatment of SARS: initial virological and clinical findings. Thorax. 2004 Mar 1;59(3):252-6. DOI: https://doi.org/10.1136/thorax.2003.012658.

24. Savarino A, Di Trani L, Donatelli I, Cauda R, Cassone A. New insights into the antiviral effects of chloroquine. The Lancet Infectious Diseases. 2006 Feb;6(2):67-9.

DOI: https://doi.org/10.1016/S1473-3099(06)70361-9.

25. Zhang $Y, X u$ Q, Sun Z, Zhou L. Current targeted therapeutics against Covid-19: Based on first-line experience in China. Pharmacological Research. 2020 Jul;157:104854. DOI: https://doi.org/10.1016/j.phrs.2020.104854.

26. Delang L, Abdelnabi R, Neyts J. Favipiravir as a potential countermeasure against neglected and emerging RNA viruses. Antiviral Research. 2018 May; 153:85-94. DOI: https://doi.org/10.1016/j.antiviral.2018.03.003.

27. Toniati P, Piva S, Cattalini M, Garrafa E, Regola $F$, Castelli $F$, et al. Tocilizumab for the treatment of severe Covid-19 pneumonia with hyperinflammatory syndrome and acute respiratory failure: A single center study of 100 patients in Brescia, Italy. Autoimmunity Reviews. 2020 Jul;19(7):102568. DOI: https://doi.org/10.1016/j.autrev.2020.102568.

28. Article O. Dexamethasone in Hospitalized Patients with Covid-19 - Preliminary Report. 2020;1-11.

29. Caly L, Druce JD, Catton MG, Jans DA, Wagstaff KM. The FDA-approved drug ivermectin inhibits the replication of SARS-CoV-2 in vitro. Antiviral Research. 2020 Jun;178:104787. DOI: https://doi.org/10.1016/j.antiviral.2020.104787.

30. Black S, Bloom DE, Kaslow DC, Pecetta S, Rappuoli R. Transforming vaccine development. Seminars in Immunology. 2020 Aug;50:101413. DOI:

https://doi.org/10.1016/j.smim.2020.101413.

31. Mathieu E, Ritchie H, Ortiz-Ospina E, Roser M, Hasell J, Appel C, et al. A global database of Covid19 vaccinations. Nat Hum Behav [Internet]. 2021 May 10 [cited 2021 Jun 14]; URL: http://www.nature.com/articles/s41562-021$\underline{01122-8}$.

32. Liu X, Liu C, Liu G, Luo W, Xia N. Covid-19: Progress in diagnostics, therapy and vaccination. Theranostics. 2020;10(17):7821-35. DOI: https://doi.org/10.7150/thno.47987. 